\title{
DYNAMIC DESIGN OF HYDRAULIC PRESSURE CONTROL VALVE OF ACTIVE SUSPENSION SYSTEM USING EXPERIMENTAL METHOD
}

\author{
Choon-Tae Lee ${ }^{1}$ and Byung-Young Moon $^{2 *}$ \\ ${ }^{1}$ Department of Automotive Mechanical Engineering, Silla University, Pusan, Korea \\ ${ }^{2}$ Department of Naval Architecture, Kunsan National University, Kunsan, Korea \\ * Corresponding author (moonby20@gmail.com)
}

\begin{abstract}
The controllability of active suspension system in automotive vehicle is strongly affected by the performance of pressure control valve. In this study, a new mathematical model and simulation model of the hydraulic pressure control valve of automotive is proposed. And proposed model of the hydraulic pressure control valve are analyzed. The effects of the main design parameters variations on the performance of the pressure control valve are investigated. To show the effectiveness of the proposed mathematical and simulation model, the analyzed results are compared with the experimental results. As a result, the proposed model of the hydraulic pressure control valve was proved as very effective one. The results reported herein will provide a better understanding of the automotive active suspension system. Moreover, it is believed that those properties of the results can be utilized in the dynamic design of the automotive system. It is believed that these studies can be contributed in automobile suspension system.
\end{abstract}

Keywords: Hydraulic Mechanics, Mathematical Model, Design of Servo System, Signal Processing, Hydraulic Valve, Active Suspension System, Vehicle Dynamics

\section{INTRODUCTION}

Recently, due to the increased advances of electronics technology and integration with hydraulic technology, active control technology has been adapted to the chassis system [1, 2]. An Active Suspension system is a system which has an external hydraulic energy source and controls each wheel's suspension load by supplying or discharging the hydraulic energy in order to obtain both good handling and ride comfort. In order to actively and instantly restrain or control undesired movements generated by the vehicle vibrations and inclinations, it is necessary for the vehicle itself to provide a power source which can always supply energies necessary for controlling. On the other hand, running on a smooth road such as a highway, the vibrations or attitude changes of vehicle do not occur so often and not much energy is needed. At first, a Full Active Suspension system with high frequency response which uses hydraulic cylinders was investigated to verify the potentiality of performance. However, such a system is not suitable for practical use, because it wastes much energy to obtain equivalent performance of ride comfort to the passive suspension system in high frequency range, and needs the high performance actuators which are very expensive. However a Slow Active Suspension was developed as a practical system which mainly controls the motions of low frequency range and the performance in high frequency range depends upon its passive characteristics [3]. The Active Suspension system for a passenger car has four functions - ride comfort control, vehicle attitude control, height control and stability control. These functions are carried out by controlling hydraulic pressure in the hydropneumatic cylinders which have gas springs supporting each wheel. In the relatively low frequency band or less than $2 \mathrm{~Hz}$, the pressure control valve receives pressure supply and discharge signals from the electric sensors, such as a G-sensor and controls in the system. In the intermediate frequency band of $2 \sim 6 \mathrm{~Hz}$, a spool valve in the 
pressure control valve senses the pressure changes and mechanically operates to keep the line pressure constant, thereby preventing the transmission of vibrations to the vehicle body[4,5].

\section{SYSTEM MODELING}

\section{The mathematical modeling of the proportional} pressure control valve

A pressure control valve in the integrated valve unit controls high pressure to necessary levels and supplies pressure to each hydro-pneumatic cylinder or returns the oil in the hydro-pneumatic cylinders to a reservoir tank to always keep the necessary the pressure in the hydraulic cylinder. The simplified structure of the quarter car hydraulic model for the active suspension system is shown in Fig. 1.

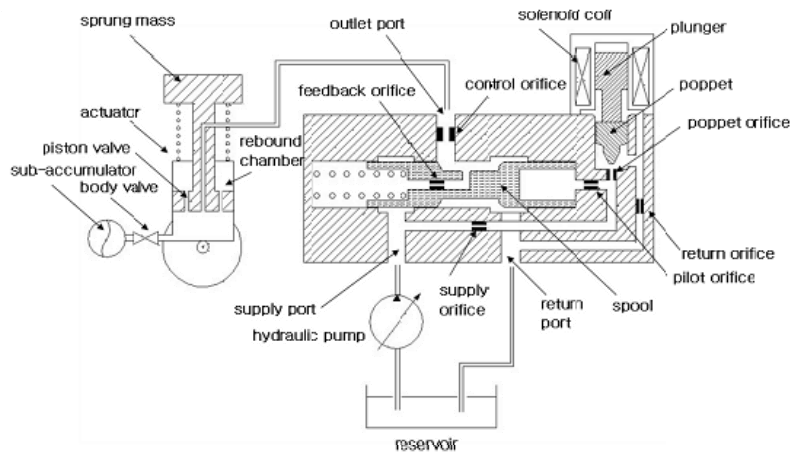

Fig. 1 The active suspension system hydraulic circuit (quarter car)

It is composed of a hydraulic pump, a valve, a hydraulic actuator and an accumulator. The valve which has been developed for the Active Suspension is a proportional pressure control valve type, because the electric current which supplied to the solenoid coil of the proportional pressure control valve controls the hydraulic pressures linearly in the hydro-pneumatic strut. The proportional pressure control valve is consist of the solenoid valve portion for generating power, the poppet valve portion for generating pilot pressure, and the spool valve portion for switching over hydraulic passages. The solenoid force is transmitted to the poppet valve to balance the pressure in the pilot pressure chamber. It means that the pressure in the pilot pressure chamber is determined by the solenoid force, i.e., the electric current value of the solenoid coil. The pressure of the pilot pressure chamber and outlet port are equalized by introducing the pressure in the pilot pressure chamber into the spool valve at one end and the pressure in the outlet port into the spool valve at the other end, thereby to obtain the same level pressure in the outlet port as that in the pilot pressure chamber, which is proportional to the solenoid electric current [6]. Fig.2 shows schematic of the proportional pressure control valve and system variables notations for the analysis.

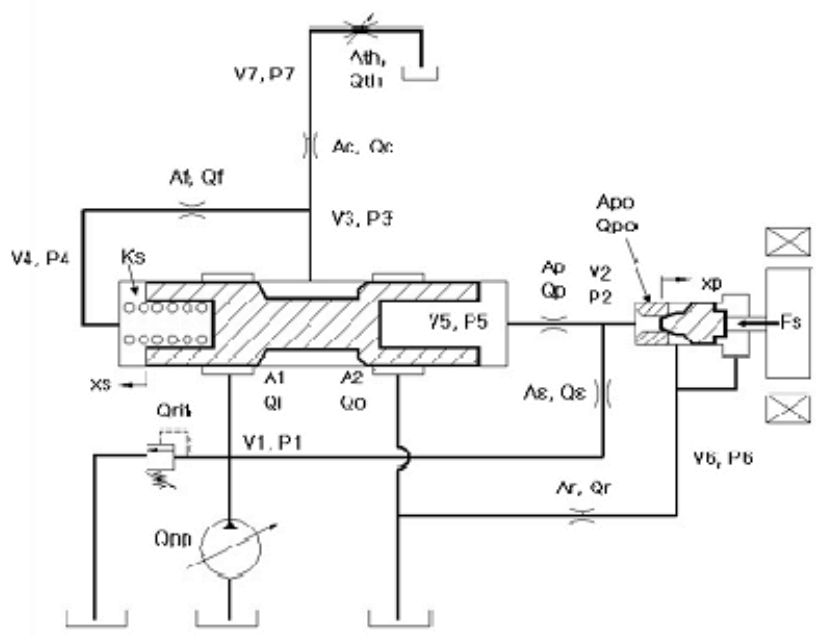

Fig. 2 Schematic of the proportional pressure control valve

Fig. 3 shows detailed schematic of the spool and poppet.
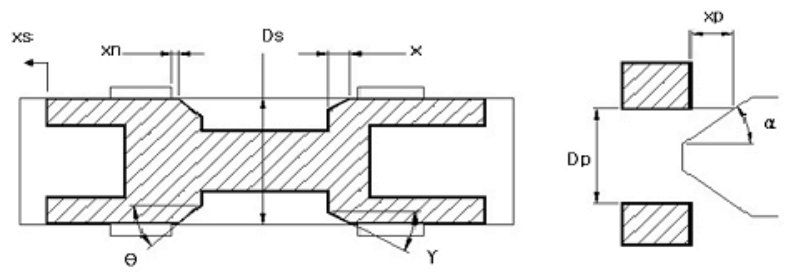

Fig. 3 Schematic of the spool and poppet

From Fig. 2, the flow equations for the proportional pressure control valve can be expressed as follows [7]; 


$$
\begin{aligned}
& Q_{i}=C_{d 1} A_{1} \sqrt{\frac{2}{\rho}\left(P_{1}-P_{3}\right)} \\
& Q_{o}=C_{d 2} A_{2} \sqrt{\frac{2}{\rho}\left(P_{3}-P_{0}\right)} \\
& Q_{p o}=C_{d p o} A_{p o} \sqrt{\frac{2}{\rho}\left(P_{2}-P_{6}\right)} \\
& Q_{s}=C_{d} A_{s} \sqrt{\frac{2}{\rho}\left(P_{1}-P_{2}\right)} \\
& Q_{p}=C_{p} A_{p} \sqrt{\frac{2}{\rho}\left(P_{2}-P_{5}\right)} \operatorname{sign}\left(P_{2}-P_{5}\right) \\
& Q_{f}=C_{f} A_{f} \sqrt{\frac{2}{\rho}\left(P_{3}-P_{4}\right)} \operatorname{sign}\left(P_{3}-P_{4}\right) \\
& Q_{r}=C_{r} A_{r} \sqrt{\frac{2}{\rho}\left(P_{6}-P_{0}\right)} \\
& Q_{c}=C_{c} A_{c} \sqrt{\frac{2}{\rho}\left(P_{3}-P_{7}\right)} \\
& Q_{t h}=C_{t h} A_{t h} \sqrt{\frac{2}{\rho}\left(P_{7}-P_{0}\right)}
\end{aligned}
$$

where, $C_{d 1}, C_{d 2}, C_{d p o}$ and $C_{d} \sim C_{t h}$ are the flow coefficients of the orifices, $A_{s}$ is an area of the supply orifice, $A_{p}$ is an area of the pilot orifice, $A_{p o}$ is an area of the poppet orifice, $A_{f}$ is an area of the feedback orifice, $A_{r}$ is an area of the return orifice, $A_{c}$ is an area of the control orifice, $A_{t h}$ is an area of the throttle valve. The sectional area of the spool $\left(A_{1}, A_{2}\right)$ and the $\operatorname{poppet}\left(A_{p o}\right)$ can be expressed as follows;

if $x_{s} \leq x_{n}, A_{1}=0$

if $x_{n}<x_{s} \leq\left(x_{n}+x\right), \quad A_{1}=\pi \sin \theta\left(x_{s}-\left(x_{n}+x\right)\right)\left[D_{s}-\frac{\left(x_{s}-\left(x_{n}+x\right)\right)}{2} \sin 2 \theta\right]$

if $x_{s}>\left(x_{n}+x\right), \quad A_{1}=\pi D_{s}\left(x_{s}-\left(x_{n}+x\right)\right)$

$A_{p o}=\pi x_{p} \sin \alpha\left[D_{p}-\frac{x_{p}}{2} \sin 2 \alpha\right]$

The flow continuity equations for the proportional pressure control valve can be expressed as follows;

$Q_{p p}-Q_{i}-Q_{r i f}-Q_{s}-\frac{V_{1}}{\beta_{o}} \frac{d P_{1}}{d t}=0$
$Q_{s}-Q_{p}-Q_{p o}-A_{p o} \frac{d x_{p}}{d t}-\frac{V_{2}}{\beta_{o}} \frac{d P_{2}}{d t}=0$

$Q_{i}-Q_{f}-Q_{c}-\frac{V_{3}}{\beta_{o}} \frac{d P_{3}}{d t}=0$

$Q_{f}+A_{\text {spool }} \frac{d x_{s}}{d t}-\frac{V_{4}}{\beta_{o}} \frac{d P_{4}}{d t}=0$

$Q_{p}-A_{\text {spool }} \frac{d x_{s}}{d t}-\frac{V_{5}}{\beta_{o}} \frac{d P_{5}}{d t}=0$

$Q_{p o}-Q_{r}+A_{p o} \frac{d x_{p}}{d t}-\frac{V_{6}}{\beta_{o}} \frac{d P_{6}}{d t}=0$

$Q_{c}-Q_{t h}-\frac{V_{7}}{\beta_{o}} \frac{d P_{7}}{d t}=0$

where $A_{\text {spool }}$ is an area of the spool and $\beta_{o}$ is the bulk modulus of oil. The dynamic equations of the spool and poppet can be expressed as follows;

$M_{s} \frac{d^{2} x_{s}}{d t^{2}}+C_{s} \frac{d x_{s}}{d t}+K_{s} x_{s}+F_{f l s}-A_{s}\left(P_{5}-P_{4}\right)=0$

$F_{f l s}=2 \cos \phi\left[C_{s i} A_{1}\left(P_{1}-P_{3}\right)-C_{s o} A_{2}\left(P_{3}-P_{0}\right)\right]$

$C_{s i}=C_{d 1} C_{v}$

$C_{s o}=C_{d 2} C_{v}$

$M_{p} \frac{d^{2} x_{p}}{d t^{2}}+C_{p} \frac{d x_{p}}{d t}+F_{f l p}-A_{p o}\left(P_{2}-P_{6}\right)+F_{s}=0$

$F_{f l p}=2 \cos \delta\left[C_{p r} A_{p o}\left(P_{2}-P_{0}\right)\right]$

$C_{p r}=C_{p o} C_{v}$

where, $M_{s}, M_{p}$ are the mass of the spool and poppet, $C_{s}, C_{p}$ are the viscous damping coefficients of the spool and poppet, $K_{S}$ is the stiffness coefficient of the return spring, $F_{f l s}, F_{f l p}$ are the flow force of the spool and poppet, $C_{v}$ is velocity coefficient, and $\cos \phi, \cos \delta$ are inflow angle.

\section{The simulation results of the proportional pressure control valve}

A simulation model [8] of the proportional pressure control valve is shown in Fig. 4. The main physical properties of the simulation model are listed in the Table 1. 
P2-14

Table 1 Physical properties of the simulation

\begin{tabular}{|l|l|}
\hline \multicolumn{1}{|c|}{ Constants } & \multicolumn{1}{c|}{ Value } \\
\hline Density of oil & $880 \mathrm{~kg} / \mathrm{m}^{3}$ \\
\hline Bulk Modulus of elasticity of oil & $1.8 \times 10^{9} \mathrm{~Pa}$ \\
\hline Mass of spool & $1.2 \times 10^{-3} \mathrm{~kg}$ \\
\hline Mass of poppet & $8.1 \times 10^{-5} \mathrm{~kg}$ \\
\hline Constant of feedback spring & $6.47 \times 10^{3} \mathrm{~N} / \mathrm{m}$ \\
\hline Area of poppet port & $4.91 \times 10^{-6} \mathrm{~m}^{2}$ \\
\hline Diameter of spool & $10 \mathrm{~mm}$ \\
\hline Overlap of spool & $0.2 \mathrm{~mm}$ \\
\hline Angle of spool & $\theta=50 \mathrm{deg}, \gamma=40 \mathrm{deg}$ \\
\hline Angle of poppet & $20 \mathrm{deg}$ \\
\hline Diameter of supply orifice & $0.3 \mathrm{~mm}$ \\
\hline Diameter of pilot orifice & $0.3 \mathrm{~mm}$ \\
\hline Diameter of feedback orifice & $0.3 \mathrm{~mm}$ \\
\hline Diameter of return orifice & $0.7 \mathrm{~mm}$ \\
\hline Diameter of control orifice & $2.5 \mathrm{~mm}$ \\
\hline
\end{tabular}

The simulation model is constructed by using the AMESIM ver4.0 of Imagine Co.. It is composed of main valve portion, pilot valve portion and solenoid portion, respectively. Fig. 5 shows the typical simulation results of the supply pressure $\left(P_{1}\right)$, return pressure $\left(P_{6}\right)$ and outlet pressure $\left(P_{7}\right)$ for the solenoid current step input. The sign is the same as that of Fig. 2. The dynamic response characteristics of the valve have $310 \mathrm{~ms}$ settled time $(2 \%)$. Fig. 6 shows the simulation results of spool displacement $\left(x_{s}\right)$ and poppet displacement $\left(x_{p}\right)$ for the solenoid current step input.

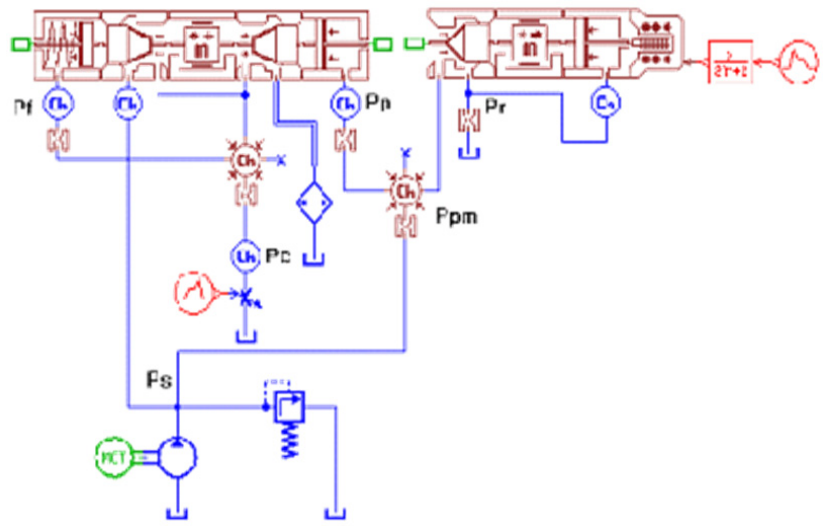

Fig. 4 Simulation model of the proportional pressure control valve

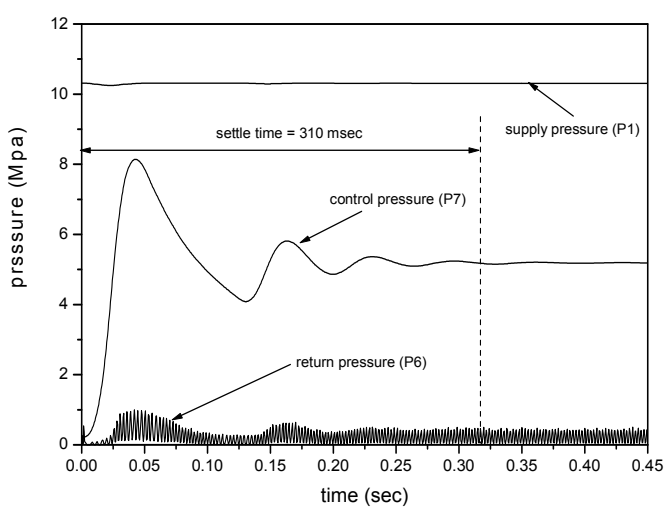

Fig. 5 Simulation results of supply return and control pressure for the solenoid current step input

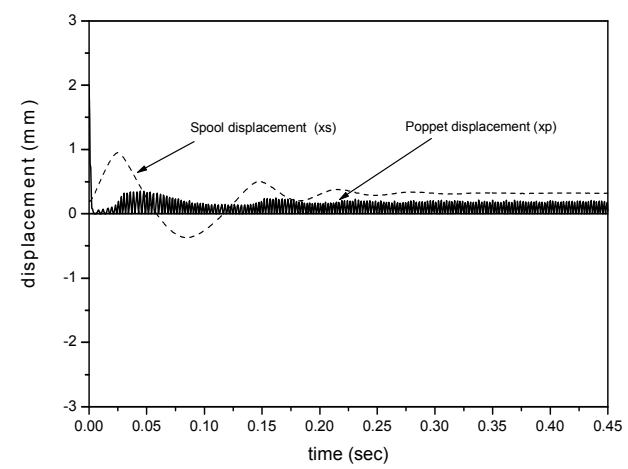

Fig. 6 Simulation results of spool and poppet displacement for the solenoid current step input

\section{The experimental results of the proportional pressure control valve}


Fig. 7 shows the schematic drawing of the proportional pressure control valve and Fig. 8 shows the photograph of the testing valve. Figure 9 shows Hydraulic circuits for the proportional pressure control valve performance test.

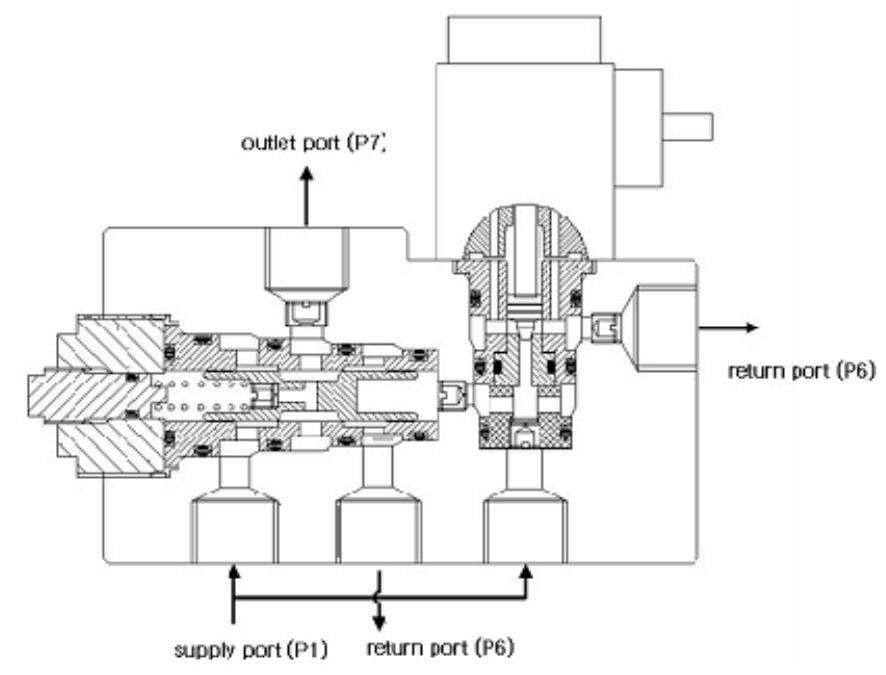

Fig. 7 Cross section of proportional pressure control valve

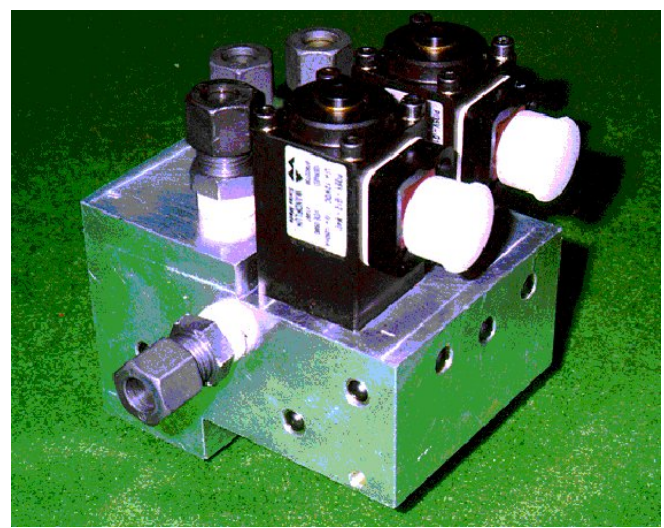

Fig. 8 Photograph of developed proportional pressure control valve

Testing circuit is composed of a hydraulic pump, a relief valve for controlling the pressure of system, a flow meter for measuring the flow rate, a pressure transducer which is strain gauge type for measuring the supply pressure and the control pressure, a variable throttle valve for hydraulic load, a data acquisition system for measuring test results, and a personal computer for controlling electric current input to the proportional pressure control valve. The supply condition of the hydraulic pump is $12 \mathrm{lpm}$ and $10.5 \mathrm{Mpa}$. The control pressure of system is set to $5 \mathrm{Mpa}$.

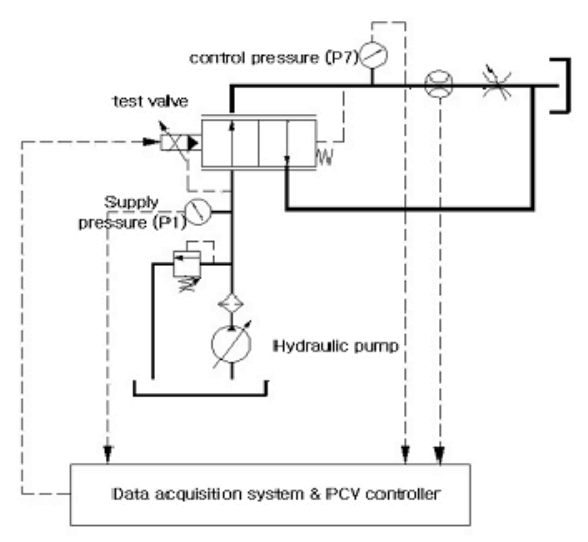

Fig. 9 Hydraulic circuits for the proportional pressure control valve performance test

The experimental result of the static characteristics of the proportional pressure control valve which is developed in this study is shown in Fig. 10. It shows that there is a dead zone where the pressure is not controlled despite current is supplied to the solenoid, caused by frictional force at the below $0.05 \mathrm{~A}$. The proportional pressure control valve controls outlet pressure linearly in the range of $0 \sim 9,8 \mathrm{Mpa}$, for the current $0 \sim 0.7 \mathrm{~A}$. This characteristics well meets the performance required by Active Suspension system and has good hysteresis characteristic which is under $4.5 \%$. The experimental result of the dynamic response characteristics is shown in Fig. 11. The experimental results shows the dynamic response of the valve is $325 \mathrm{msec}$ on the basis of the settled time (2\%). The comparison between Fig. 5 and Fig. 11 shows about $15 \mathrm{msec}$ discrepancy in settling time exists but the control pressure is coincided with each other as $5 \mathrm{Mpa}$. As a result, the experimental results coincide with simulation results well. 


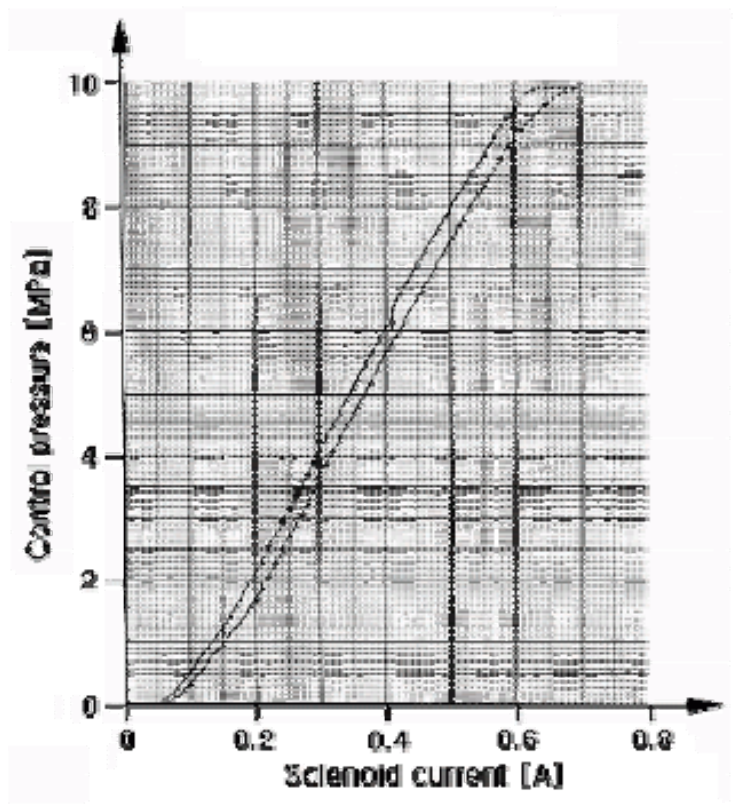

Fig. 10 Static characteristic of the developed valve (Experimental result)

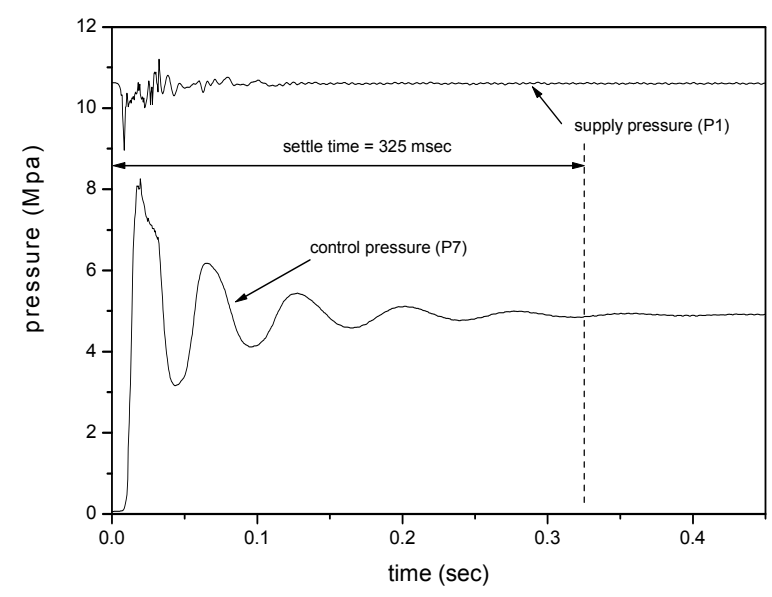

Fig. 11 Dynamic response of the developed valve

(Experimental result)

\section{Conclusion and Discussion}

In this paper we understood the structure and principle, simulated and experimented the static and dynamic characteristics for development of the proportional control valve which is an important part in the active suspension system. The following results have been obtained form this study.
(1) We proposed the mathematical and simulation model of the proportional pressure control valve for the Active Suspension system.

(2) It is confirmed that the simulation results are coincided with the experimental results well.

(3) The proportional pressure control valve which has good performance and suitable for applying to the Active Suspension system has developed. Therefore, it is expected that the valve developed in this study can be applicable for more applications such as construction machinery and other vehicle hydraulic control system.

\section{References}

[1] F. Gay, N. Coudert and I. Rifqi, Development of Hydraulic Active Suspension with Feedforward and Feedback Design, SAE 2000-01-0104

[2] J. Emura, S. Kakizaki, F. Yamaoka and M. Nakamura, Development of the semi-active suspension system based on the Sky-hook damper theory, SAE 940863, 1990

[3] G.P. Wright, and A.D. Williams, The Application of Active Suspension to High Performance Road Vehicles, Proc. Instn Mech. Engrs. Part D, 1990, 204, pp. 23-28.

[4] M. Sugihara, T. Furukawa, O. Komazawa, M. Okade, Y. Yokoya and S. Buma, Development of Control Valves for Active Suspension Systems-Development of Linear Pressure Control Valve for Car, Proceeding of JSAE 199010, 1990, pp. 361-364.

[5] H. Matsushita, T. Noritsugu and T. Wada, Optimal Control of Active Air Suspension, Transactions of the JSME, C, 1990, 56(526), pp. 1178-1183.

[6] B.H. Cho, J.S. Oh and W.H. Lee, Modeling of Pulse Width Modulation Pressure Control System for Automatic Transmission, SAE 2002-01-1257

[7] E.M. Herbert, Hydraulic Control Systems, John Wiley \& Sons, 1967, pp. 76-131.

[8] V. Nanda and V. Subbarao, Computer Modeling and Simulation of Hydraulic Systems, SAE 981978 